\title{
Estrategias de inserción y circulación de migrantes senegaleses recientes en la Ciudad Autónoma de Buenos Aires
}

\author{
Insertion and circulation strategies of recent \\ Senegalese migrants in Buenos Aires
}

Gisele Kleidermacher*

\begin{abstract}
Resumen: El presente artículo se propone analizar las principales estrategias de inserción que adoptan los migrantes senegaleses que han arribado a la Ciudad Autónoma de Buenos Aires en las últimas dos décadas, prestando especial atención a los factores que inciden en ellas, es decir, características del colectivo y de la ciudad de destino. Mediante una metodología cualitativa basada en entrevistas en profundidad al colectivo senegalés, así como observación participante en la vía pública, se analizan los obstáculos y estrategias que intervienen en su inserción, entendiendo a la migración como una experiencia total, donde confluyen características y experiencias previas a la partida y posteriores a la misma.
\end{abstract}

Palabras clave: Migrantes senegaleses. Buenos Aires. Circulación. Estrategias. Economía étnica.

Abstract: This article analyzes the main insertion strategies adopted by Senegalese migrants who have arrived to Buenos Aires in the last two decades. The focus is on the factors that affect them, i.e. the characteristics of the group and of the destination city. The research methodology has been qualitative, based on in-depth interviews with the Senegalese group, as well as participant observation in public spaces. By understanding the migration process as a total experience, this article aims to analyze the obstacles and strategies involved in the integration of the migrants, which involves some particular characteristics and some experiences before and after their departure.

Keywords: Senegalese migrants. Buenos Aires. Circulation. Strategies. Ethnic economy.

\footnotetext{
* Doctora en Ciencias Sociales por la Universidad de Buenos Aires (UBA, Argentina). investigadora Conicet, Instituto de Investigaciones Gino Germani, profesora en la carrera de Sociología en la UBA <kleidermacher@gmail.com>.
} 


\section{Introducción}

El presente artículo se desprende de la tesis doctoral titulada Miradas sobre la otredad. Producción de representaciones sociales en torno a migrantes senegaleses y argentinos en la Ciudad Autónoma de Buenos Aries entre los años 1995 y 2014, con sede en la Universidad de Buenos Aires. Dentro de dicha temática, resulta fundamental comprender el proyecto migratorio de los jóvenes senegaleses como una totalidad, desde sus orígenes, donde intervienen factores culturales, históricos, económicos y religiosos, hasta su llegada al destino, donde encuentran diversas trabas a las deben enfrentarse.

La perspectiva de trabajo ha sido una metodologia cualitativa, consistente en la realización de observación participante en la vía pública, en reuniones de la Asociación de Residentes Senegaleses en la Argentina (ARSA), en festividades religiosas y otros encuentros. Asimismo, se realizaron 50 entrevistas semiestructuradas a migrantes de origen africano subsahariano (mayoritariamente senegalés) y 21 entrevistas en profundidad a migrantes senegaleses con un mayor dominio del idioma español. Dicho corpus de datos fue grillado y analizado bajo la metodología de la teoría fundamentada. ${ }^{1}$

Tras caracterizar al colectivo senegalés en la Argentina, se presenta una breve descripción del destino, Buenos Aires, bajo los resultados de la aplicación de las políticas neoliberales con su impacto en el mercado del empleo y de la vivienda. Hacia el final del escrito se reflexiona respecto a la particular circulación de migrantes de origen Senegalés residentes en la Ciudad Autónoma de Buenos Aires, entendiendo que la misma forma parte de estrategias para sortear las limitaciones que una sociedad neoliberal impone, y ante las cuales tienen gran influencia sus tradiciones, su religión, las redes de parentesco y paisanaje, así como sus trayectorias previas.

\section{Breve caracterización del colectivo migratorio}

El movimiento migratorio de población procedente del África Subsahariana hacia la Argentina² se inicia alrededor de la década de 1990. Sus causas son principalmente económicas aunque se combina con temores ligados a persecuciones políticas. En este período llegaron al país inmigrantes

\footnotetext{
${ }^{1}$ Se realizó inicialmente una codificación abierta según la metodología de Strauss y Corbin para estimular el descubrimiento de categorías, propiedades y dimensiones de análisis. Posteriormente implementé la codificación selectiva en la búsqueda de un proceso de reducción de categorías, facilitando el entrelazamiento de codificación-grillado, análisis de contenido de los discursos e interpretación de la información obtenida.

${ }^{2}$ Excluyendo a la migración forzosa durante la colonización española y la posterior migración procedente de Cabo Verde extendida entre fines del siglo XIX y mediados del XX.
} 
de Senegal, Nigeria, Malí, Sierra Leona, Liberia, Ghana y Congo, así como afrodescendientes provenientes de países latinoamericanos, principalmente Perú, Brasil, Cuba, Colombia, República Dominicana y Haití.

Respecto a la cuantía de la población senegalesa, no existen cifras exactas, debido a la irregularidad en el ingreso y la falta de papeles hasta fechas recientes. Debido a que no hay representación diplomática entre Argentina y Senegal, la documentación ha sido un problema frecuente en la vida de los migrantes. Sin embargo, entre enero y julio de 2013 se llevó a cabo un plan de regularización migratoria para migrantes originarios de Senegal y República Dominicana, estableciendo un criterio de excepción a la Ley de Migraciones 25.871, de manera que se excluye el requisito de ingreso legal antes de la puesta en marcha del programa. Bajo el mismo se han realizado 1022 regularizaciones de acuerdo al actual presidente de la $\mathrm{ARSA}^{3}$ No obstante, y de acuerdo con miembros de la comunidad, podrían llegar a ser cerca de 5000 los senegaleses que actualmente se encuentran en el país, mientras que otros afirman que el número es menor, debido a la gran cantidad de jóvenes que han decidido asentarse en Brasil, a causa de las dificultades encontradas en la Argentina en los últimos años.

Al interior de la comunidad senegalesa se halla una preeminencia del género masculino. Como apunta Kaplan (2003, p.9), el rol de emigrar, en la sociedad de origen ha correspondido tradicionalmente al hombre. Las mujeres permanecen en el hogar, realizando tareas domésticas y generando los medios de subsistencia para la supervivencia del grupo, "como primeras productoras de alimentos, reproductoras biológicas y culturales, cuidadoras y administradoras de la economía doméstica".

De acuerdo a las investigaciones adelantadas por Maffia y Agnelli (2008), las mujeres emigran en gran parte por iniciativa de su cónyuge u otros parientes, una vez que éstos ya están asentados en el lugar de destino. Sin embargo, se observa que aún es muy pequeño el porcentaje de reagrupaciones familiares en Buenos Aires, principalmente debido a la restrictiva legislación migratoria argentina a la que me referiré posteriormente, y en segundo lugar, debido a la percepción de la migración por parte de los senegaleses como un fenómeno transitorio y no definitivo, así como las dificultades económicas que implican trasladar a su familia hacia la Ciudad de Buenos Aires, situada al otro lado del océano Atlántico.

\footnotetext{
${ }^{3}$ Entrevista realizada al Presidente de la Asociación de Residentes de Senegal en la Argentina. Cabe aclarar que en el año 2004 se realizó otro plan de regularización extraordinario donde pudieron acogerse los senegaleses residentes en el país hasta aquel entonces.
} 
Es por ello que se trata en su entera mayoría de hombres jóvenes, que tienen entre 20 y 35 años de edad, solo unos pocos sobrepasan los 40 años. En relación a su origen, se observa una distinción que tiene repercusión en su formación educativa. Ello se debe a que, aquellos que han nacido en pueblos rurales o bien en pequeñas aldeas de Senegal, han sido mayoritariamente formados en escuelas coránicas, sin regulación estatal, donde, a cargo de un morabito, dividían su tiempo entre el estudio del Islam y el cultivo de campos. A diferencia de ellos, quienes han nacido en grandes ciudades como Dakar, Casamance y Saint Louis, han sido instruidos en escuelas de regulación estatal, ya sean públicas o privadas, aprendiendo el idioma francés y en muchos casos, alcanzando estudios superiores.

En relación a la composición familiar, gran parte de los entrevistados han dejado en Senegal familias extensas con las cuales vivían, compuestas de padre, madre, hermanos, tíos, cuñados y en algunos casos mujer/es e hijos que quedan viviendo con la familia del hombre que migra, y a quienes envía remesas mensualmente.

Respecto a sus trayectorias migratorias, cuentan con escalas previas antes de su llegada a la Argentina entre las que se enumeran países de África, Europa y Brasil en Sudamérica. Sin embargo reconocen preferir a la Argentina porque "acá es tranquilo", "Francia es racista" y "la policía no molesta tanto". En su gran mayoría llegaron en avión desde Dakar, capital de Senegal, hasta San Pablo o Fortaleza ${ }^{4}$ y luego en ómnibus o tren hasta Buenos Aires. En cuanto a sus trayectorias laborales en Senegal, se observan contrastes. Numerosos jóvenes se dedicaban al comercio, principalmente de indumentaria, algunos lo hacían en la vía pública al igual que lo hacen en Buenos Aires, mientras que otros contaban con negocios en ferias o bien comercios. Asimismo, varios jóvenes refirieron contar con conocimientos y experiencia en el desempeño de profesiones, ya sea en la producción de artesanías (tallado de madera y marfil), otros como electricistas, albañiles, carpinteros y mecánicos. Por último se encuentran también choferes, tanto de camiones como de taxis. ${ }^{5}$

Cabe aclarar que son diversos los factores que intervienen en la partida de los jóvenes senegaleses de su país, las mismas exceden el presente escrito, no obstante lo cual, destacan la diversificación de los ingresos familiares

\footnotetext{
${ }^{4}$ Ciudades de Brasil que cuentan con vuelos directos desde Dakar, Senegal.

${ }^{5}$ Datos obtenidos en base a 50 entrevistas semiestructuradas realizadas en la vía pública a vendedores ambulantes senegaleses en los barrios de Balvanera, Liniers, Flores y Floresta y 20 entrevistas no estructuradas realizadas a senegaleses con una residencia más prolongada en la Ciudad Autónoma de Buenos Aires y mayor dominio del español, lo que facilitó la realización de las mismas.
} 
mediante el envío periódico de remesas, principalmente debido a la gran migración del campo a la ciudad, la cual no puede ofrecer empleo a toda su población. Esta migración también tiene como trasfondo las políticas neoliberales que las agencias internacionales han aplicado desde la década del 80. No me extenderé sobre la problemática del subdesarrollo del continente. Basta mencionar que desde las independencias de los países africanos en la década de los 60 y 70, gran parte de los países del continente han retrocedido a un régimen prácticamente preindustrial, pues su participación en el mercado mundial se limita a la venta de productos agrícolas y materias primas, sector que tiene un carácter de enclave en sus respectivas economías como observa Kabunda (2012). ${ }^{6}$

Otros factores pueden encontrarse en la búsqueda de crecimiento personal mediante la experiencia en el exterior que los jóvenes anhelan como un paso hacia la adultez, también el ahorro individual, el cual no es posible realizar al formar parte de familias ampliadas con diversas necesidades, por último, la vivencia por fuera de la mirada atenta de los mayores, tanto familiares como vecinos y parientes, lo cual forma parte de una tradición muy arraigada en la sociedad senegalesa, tanto urbana como rural. ${ }^{7}$

Es la combinación de estos factores -entre los que el económico tiene una mayor preponderancia- sumados a la larga tradición migratoria de los pobladores de Senegal (fomentada en muchos casos por la colonización francesa), y la tradición Mouride ${ }^{8}$ (cofradía surgida en el marco de la fe musulmana, a la que mayoritariamente adscriben los senegaleses tanto en origen como en los países de destino), las que confluyen en el proyecto migratorio, cuyo resultado es su presencia en la Ciudad Autónoma de Buenos Aires.

\footnotetext{
${ }^{6}$ La reducción de las ayudas del estado y las privatizaciones han suscitado un cambio importante que se hace visible en las famosas "pateras". Antes, miles de senegaleses utilizaban los cayucos en la pesca atlántica, pero desde que el presidente Abdoulaye Wade firmó concesiones de pesca con diversas firmas de grandes barcos extranjeros esta actividad ha dejado de ser su medio de vida. El uso que ahora muchos ex pescadores dan a esos cayucos es de transporte hacia las islas Canarias. Del dinero pagado por las concesiones, nada llega a la población.

7 Para ampliar en el tema consultar Kleidermacher (2013).

${ }^{8}$ Los inicios de la cofradía mouride y su relación con las migraciones suelen situarse en el año 1912, cuando Cheik Amadou Bamba, su creador, organizó la "colonización de tierras nuevas" dado que las tierras donde empezó el cultivo del cacahuete se estaban agotando. También por ello se suele encontrar un paralelismo entre la expansión mouride y la penetración del capitalismo agrario desde el país wolof hacia territorios donde el colonialismo todavía no estaba presente. En un medio hostil, en tierras áridas, controladas por los pastores peul, los morabitos organizaron la instalación de los talibé, que de forma disciplinada consiguieron hacer crecer el cacahuete y expulsar a los peul, siempre bajo la protección de la metrópoli (Crespo, 2007).
} 


\section{Breve caracterización del destino: Buenos Aires y el neoliberalismo}

La Ciudad Autónoma de Buenos Aires es la capital de la República Argentina y una de las principales ciudades de América Latina. A pesar de que posee límites precisos que delimitan su jurisdicción política y administrativa, la ciudad capital forma parte de un extenso continuo urbano que recibe el nombre de Aglomerado Gran Buenos Aires, que se expande desde la Capital Federal hacia la periferia.

Tradicionalmente, la producción de la Ciudad de Buenos Aires se basó en algunas políticas del gobierno municipal, fundamentalmente la producción de obras públicas que dieron una fuerte centralidad, y la producción privada con regulación municipal de los servicios, especialmente energía eléctrica y transportes (ferrocarriles, tranvías y autobuses), así como la producción y gestión estatal de la red de agua y saneamiento. Sobre esa base se expandió la ciudad incorporando suelo producido privadamente, estando a cargo de los ocupantes la iniciativa para completar el medio construido (Pírez, 2006).

Ahora bien, en la Argentina, las políticas neoliberales comenzaron a ser aplicadas a partir del gobierno militar implantado con el golpe de estado de marzo de 1976. Desde entonces, se revertió el modelo de industrialización por sustitución de importaciones, provocando desempleo y fuerte deterioro de la distribución económica. El gobierno central se retiró de las políticas sociales más importantes en infraestructura (agua y saneamiento y distribución eléctrica), salud y educación, descentralizando en primer lugar hacia los gobiernos provinciales y luego hacia los municipios. Se inició un proceso general al que Pírez (2009) caracteriza como disminución del estado, con la baja de su gasto social.

A partir de 1991, y bajo el gobierno del presidente Menem, esas políticas se consolidaron y ampliaron en un proceso de desregulación y apertura de la economía, de la mano de la privatización y concesión de empresas estatales y servicios públicos, severas medidas de estabilidad monetaria (Plan de Convertibilidad) y la puesta en marcha del Mercosur. Observa Ciccolella (2009) que el resultado fue un escenario macroeconómico expansivo, sumamente atractivo para una nueva generación de inversiones; en particular inversión extranjera directa, dirigidas fundamentalmente al sector servicios y a la adquisición de empresas, muy especialmente las del complejo agroalimentario, provocando una acelerada globalización de la economía argentina hacia fines de esta década. 
En cuanto a la Ciudad de Buenos Aires, también el estado disminuyó sus acciones directas sobre el territorio, en un contexto de reforma y achicamiento del aparato estatal, con disminución de funciones y recursos, se transfirieron tareas a otros niveles estatales (descentralización) y hacia empresas privadas (privatización) y pasó a actuar como promotor del mismo y acondicionador según las necesidades del capital privado. Esos años mostraron la presencia cada vez mayor del capital transnacional en la economía del país, y particularmente el peso del capital financiero, así como el predominio económico del sector terciario (finanzas y servicios) y el crecimiento de las actividades destinadas a la exportación. A partir de la aplicación de dichas políticas se amplió la brecha entre los sectores más ricos y más pobres de la ciudad, de acuerdo a las observaciones de Ciccolella (2009).

Es en ese contexto en el que arriban los migrantes senegaleses, encontrando diversos obstáculos para su inserción. Son dos las problemáticas que más frecuentemente son mencionadas en las entrevistas, las cuales serán abordadas en los siguientes apartados: la vivienda y el empleo.

\section{Inserción habitacional}

Si bien la cuestión habitacional formó parte de las problemáticas a lo largo de la historia de la ciudad, en las dos últimas décadas se ha acentuado la polarización en cuanto a la vivienda: de un lado se han ampliado las villas y surgido nuevos asentamientos, inquilinatos, pensiones, alojamientos temporarios, situaciones de calle y otras formas de hábitat precario; por otra parte, la mayor concentración de ingresos así como el nuevo rol del estado, las inversiones externas y el mercado inmobiliario dieron lugar a una oferta orientada principalmente al consumo de viviendas de lujo y segunda vivienda para sectores de ingresos medios y altos.

Tanto por la evolución de la pobreza como por los precios que expulsan del submercado de viviendas de alquiler, los grupos de población de menores recursos han debido buscar diversas estrategias de supervivencia, siendo los migrantes económicos que llegan a la ciudad en busca de mejores condiciones de vida y de oportunidades laborales, quienes suelen engrosar estos grupos.

En este panorama de polarización social, achicamiento del estado, y privatización de los bienes de consumo colectivo arriban los migrantes de origen senegalés a la Ciudad Autónoma de Buenos Aires, quienes, junto a otros grupos de menores recursos que no pueden acceder a una vivienda de alquiler, han debido buscar diversas estrategias de supervivencia. En los últimos años la falta de políticas habitacionales y el mercado inmobiliario orientado a las capas sociales de ingresos medio-altos ha profundizado los 
problemas habitacionales. Es por ello que los sectores empobrecidos deben buscar alternativas por fuera de dicho mercado mientras el estado no ofrece soluciones.

[...] los africanos no alquilamos casa sino habitación, no nos dejan alquilar, piden garantía y nosotros no tenemos, sino piden mucha plata para depósito y no podemos conseguir. (Hombre senegalés, 23 años. Entrevista realizada el 20 de Diciembre de 2011)

Algunos datos estadísticos revelados por Mazzeo y Roggi (2012) dan cuenta de esta situación: en 2008, los hogares que residían en inquilinatos, hoteles familiares, pensiones y casas tomadas representaban el 5\% del total de hogares de la Ciudad Autónoma de Buenos Aires. La mayoría lo hacía en piezas de pensión-hotel familiar $(61,1 \%)$; seguían en importancia las piezas de inquilinato $(32,4 \%)$; y era mínimo el porcentaje de los que habitaban casas tomadas (6,5\%). En cuanto a la distribución espacial: el 67,5\% de los hogares se concentraba en cuatro comunas ${ }^{9}$ de la ciudad, ubicadas en la zona sudeste y suele estar relacionada con la imposibilidad de sus miembros de acceder a empleos con mayor estabilidad o con remuneración más elevada.

Es en este contexto que los migrantes senegaleses deben encontrar una solución para la problemática habitacional. Debido a la imposibilidad de acceder a una vivienda de alquiler, ya sea por no contar con las garantías que se solicitan a tal fin, por los prejuicios ${ }^{10}$ que pesan sobre este colectivo, pero principalmente por los altos costos que ello implica, han optado por el alquiler de habitaciones en hoteles pensión, donde no se solicitan garantías y los costos no son tan altos. ${ }^{11}$

${ }_{9}^{9}$ La Ciudad de Buenos Aires se encuentra organizada en 15 Comunas que se rigen bajo la Ley 1.777 sancionada en 2005. Se trata de unidades descentralizadas de gestión política y administrativa que, en algunos casos, abarcan a más de un barrio porteño. Las Comunas tienen competencias exclusivas y concurrentes con el gobierno de la Ciudad. Entre las primeras, se encuentran el mantenimiento de las vías secundarias y los espacios verdes, la administración de su patrimonio, la iniciativa legislativa y la elaboración de su presupuesto y programa de gobierno.

${ }^{10}$ De acuerdo a las investigaciones realizadas por Checa (1998) en España, donde, como mencionamos, la migración senegalesa cuenta con una antigüedad mayor a 30 años, los argumentos para no alquilar pisos a migrantes africanos se basan principalmente en el desconocimiento y por lo tanto, la formulación de prejuicios acerca de sus pautas culturales que serían contrarias a las de la sociedad nativa.

${ }^{11}$ El surgimiento de los hoteles-pensión puede remontarse a la segunda mitad de la década de 1950, cuando ex-propietarios de edificios en los que funcionaban previamente inquilinatos comenzaron a utilizar el sistema de hospedaje con el propósito de evadir las restricciones impuestas sobre los alquileres. Esta modalidad representó una nueva forma de apropiación de la renta urbana (Cuenya et al. 1988). Con el retorno a la democracia, se establecieron desde el estado medidas que buscaban regular este sector, protegiendo los derechos de los residentes. 
Los hoteles-pensión cuentan con características físicas y de ocupación similares a la de los inquilinatos; no obstante, su diferencia radica en la relación que tiene el habitante con el propietario: ésta se entabla a partir de la condición legal de "pasajeros", dado que se encuentran sometidos al régimen de hotelería aunque su estancia sea permanente (Mazzeo y Roggi, 2012).

La condición de habitabilidad en estos lugares suele entenderse como una situación habitacional precaria, debido a que no satisface ciertos requisitos básicos como las necesidades de intimidad y tranquilidad familiar, de abrigo y protección contra las inclemencias del medio ambiente, de seguridad en la tenencia de la vivienda y en la accesibilidad en el precio, de dotación de los servicios necesarios (agua, luz, gas, etcétera) y de condiciones que preserven la salud de sus habitantes. En el caso que analizamos, podemos señalar que se comparte el baño y/o cocina con otros hogares y no se cuenta con ventilación e iluminación natural de la/s pieza/s, así como también son frecuentes los problemas de humedad en las paredes y techos de las habitaciones. Esto ha sido relatado por los propios migrantes en algunas de las entrevistas mantenidas:

Cuando llegué acá a Argentina lo que me sorprendió es ver los chicos, los senegaleses, que están viviendo, si yo veo lo que están durmiendo y donde están durmiendo acá es mucho mejor en Senegal. Cuando entramos a la pieza del amigo que me recibió estaban durmiendo todos pegaditos, nosotros no dormimos así pegaditos, eso me sorprendió primero y muchas cosas, una valija acá, una valija allá, una taza acá, una pava allá, eso me sorprendió, no es el país que me imaginaba. (Hombre senegalés, 26 años, entrevista realizada en Julio de 2010)

Si bien el hecho de vivir con compatriotas forma parte de elecciones personales que los senegaleses realizan, tanto para preservar sus costumbres tradicionales -como comer y rezar juntos-, así como también para contrarrestar el desarraigo y fortalecer sus redes de contención; las condiciones de vida en los hoteles suelen ser resaltadas en las entrevistas como deficientes. Las quejas por la falta de calefacción, las malas condiciones de higiene, la falta de ventilación, el cobro excesivo en el precio de las habitaciones y otros factores que afectan su vida diaria son reiteradas.

La reinstalación de la figura legal de "locación encubierta" para el arriendo de piezas en establecimientos hoteleros, pensiones y residenciales sin habilitación oficial es una muestra de este tipo de disposiciones. Sin embargo, y de acuerdo a las observaciones de Mazzeo y Roggi (2012), la falta de controles efectivos terminó sosteniendo la rentabilidad de este tipo de alojamiento. 
Asimismo, los hoteles-pensión se hallan segregados residencialmente por el espacio en donde se ubican: si bien se encuentran dispersos en los barrios porteños, poseen una mayor concentración en el sudeste de la ciudad (Mazzeo y Roggi, 2012). Razón por la cual, a las malas condiciones físicas, se suman las dificultades de residir en barrios segregados, empobrecidos, donde las inversiones estatales son muy deficientes debido a que no son relevantes para el mercado inmobiliario.

Entre los barrios donde se concentran los senegaleses contamos Liniers, Balvanera, Flores y Constitución, si bien no conforman barrios étnicos con negocios de y para la comunidad senegalesa, su concentración habitacional en esos puntos geográficos así como para la realización de la venta ambulante -tema que será desarrollado en el próximo apartadoconlleva a que sus vínculos se reduzcan al trato con la población que allí se concentra, coincidiendo con la distribución socioeconómica de la ciudad. Eso es, sectores donde pesan estigmas, relacionados con la pobreza, el delito y por lo tanto, que estrechan las oportunidades de integración y relación con el resto de la población.

En este sentido, observa Rodríguez (2008) que la segregación conduce al aislamiento y estrecha los horizontes de movilidad social al reducir las posibilidades de interacción con otros grupos sociales y su acceso a lugares de empleo, centros educativos y de salud. "La reunión en un lugar de una población homogénea en cuanto a su desposeimiento, tiene también como efecto, redoblar el desposeimiento" (Bourdieu y Wacquant, 1992, p.261 en Wacquant, 2007, p. 195). Para el caso de la población senegalesa en la Ciudad Autónoma de Buenos Aires, esta situación permea su realidad, ya que su asentamiento se concentra en los barrios "menos deseables" de la ciudad, barrios degradados, que concentran población migrante no deseada, pobre, y que suele ser asociada a la delincuencia.

Retomando las ideas de Bourdieu (1988), el espacio social se define por la exclusión mutua (o la distinción) de las posiciones que lo constituyen, de esta forma, se presenta como la consecuencia de la distribución en el espacio físico de las posiciones de los sujetos en el plano simbólico. Quienes carecen de capital son mantenidos a la distancia física o simbólica de los bienes socialmente más escasos. Pero a estos problemas deben sumarse las dificultades que aún encuentran para poder alquilar habitaciones en dichos hoteles-pensión:

Yo estaba buscando habitación, estaba el cartel y cuando fui me dijeron que ya estaba ocupada, le pedi a una chica blanca que fuera y se la alquilaron. (Hombre senegalés, 25 años, entrevista realizada en Diciembre de 2011) 
A veces en los hoteles uno puede entrar, y cuando se enteró que hay una habitación disponible llama a otro para que lo tome. A veces los hoteles te dicen cualquier cosa para no darte una habitación. (Hombre senegalés, entrevista realizada el 7 de Julio de 2012)

Acá en Buenos Aires también me pasó, fui a un hotel a preguntar si había habitación y me dicen, acá alquilan nomás a argentinos, es feo, eso es discriminación total. (Hombre Senegalés, entrevista realizada el 13 de Diciembre de 2012)

Podemos notar a partir de los anteriores relatos que, aún en los espacios segregados residencialmente donde se encuentran los hoteles pensión, la presencia de la población de origen senegalés no es valorada, reforzando los estigmas que sobre ellos caen, enrareciendo sus posibilidades de integración en igualdad de condiciones con el resto de la población. De esta forma, a la escasez de recursos materiales que los obliga a buscar viviendas en los barrios más excluidos y donde es más económica la vivienda, también deben recurrir a los hoteles más marginales y con peores condiciones de habitabilidad, ya que serían quienes ofrecen menos resistencia a recibirlos.

\section{Inserción laboral mayoritaria}

El trabajo es el ámbito por excelencia de integración de los sujetos a la sociedad receptora. De allí que diversos autores coinciden en que la "buena integración" viene definida por la realización de un trabajo formal, mediado por un contrato laboral. Ello se debe a que, de acuerdo a la legislación laboral argentina, el tener un contrato laboral formal conlleva la obtención de una cobertura de salud privada, aportes jubilatorios y otros beneficios que permiten mayor tranquilidad al trabajador. ${ }^{12}$ Asimismo, el compartir un ámbito laboral diariamente genera mayores contactos con la población local-aunque ellos no estén exentos de conflictos-. Sin embargo ello no es sencillo, como observa Mármora (2004), la movilidad de mano de obra no calificada ya no es necesaria para ciertos procesos de producción, entonces, en lugar de circular armoniosamente con los demás factores de producción, es excluida por la nueva dinámica de estos, están condenadas cada vez más a la ilegalidad por parte de las normas que rigen el movimiento de las personas a través del mundo. Este "excedente" de población desde algunos países no va a encontrar

\footnotetext{
${ }^{12}$ El régimen laboral argentino se encuentra regulado por una serie de leyes entre las que destacan: Ley de régimen laboral no 25.877, Ley de Contrato de trabajo no 20.744 , Ley de protección del trabajo no 24.013. Asimismo existen convenios colectivos de trabajo en los que se establecen acuerdos salariales y condiciones laborales para un sector específico. Para ampliar información ver: <www.argentina.gob.ar/información/trabajo/163-régimen-laboral.php> (1. ago. 2014).
} 
su complementariedad en la "escasez" en otros como ocurrió a principios del siglo XX. Hoy las migraciones no son vistas como un aporte al desarrollo sino como una amenaza por parte de los países receptores.

Asimismo, las políticas orientadas al mercado de trabajo a través de la privatización, desregulación y pérdida de poder de los sindicatos, han provocado un profundo impacto en sectores importantes de la población de las ciudades al generar desempleo y precarización laboral. Estos factores, combinados con la falta de inversión estatal en servicios públicos, aumentan los niveles de pobreza con un profundo impacto en la ciudad, ya que dejan fuera del acceso a los bienes urbanos a sectores importantes de la población. ${ }^{13}$

La actividad económica predominante del colectivo senegalés en la Ciudad Autónoma de Buenos Aires es la venta ambulante de bijouterie. Ante la fragmentación y precarización del mercado laboral y el aumento del desempleo y el subempleo. Esta situación genera dificultades para la integración y plantea interrogantes acerca de las perspectivas de futuro para este colectivo. La estructura de nuestro país no brinda, en cuanto a oportunidades, un cambio radical en la situación de inseguridad en la que vivían estos migrantes en su país de origen.

Asimismo, la venta ambulante de bijouterie a la que se dedican la mayoría de los migrantes senegaleses lleva implícita un factor de riesgo, ya que las personas están "infringiendo" el Código Contravencional vigente, que según el artículo 83 prohíbe "impedir u obstaculizar la circulación de personas o vehículos por la vía pública o espacios públicos, salvo que sea en ejercicio de un derecho constitucional, y se haya dado previo aviso a la autoridad competente". Si bien existen opiniones contrapuestas en relación a este artículo del Código, en la práctica los vendedores ambulantes sufren multas y decomisos por ocupar con mercadería veredas y paseos públicos. En algunos casos, esto los obliga a pagar, como ellos mismos dicen, "coimas" o "alquileres para permanecer en un lugar", así como también multas para retirar mercadería decomisada por la policía y a cambiar constantemente de lugar. Además, actualmente la política del gobierno porteño, de prohibir las actividades callejeras de mera subsistencia como la venta ambulante y la prostitución, ha profundizado la

\footnotetext{
${ }^{13}$ En este sentido, observa Pírez que todo esto es parte de una particular relación mercado-estado, donde el mayor predominio privado está asociado con tres situaciones: a) el estado disminuye o debilita su intervención, con un sesgo en favor de la producción privada del espacio urbano; b) el estado modifica el sentido de su intervención, orientándose no ya en razón de los "intereses generales" sino en favor de intereses económicos particulares, y c) la emergencia de un desequilibrio en la relación mercado-estado por la transformación de los actores capitalistas, como puede ser un proceso de internacionalización, que altera su peso relativo frente al estado y al resto de los actores sociales (Pirez, 2006, p. 33).
} 
represión. Esta situación de inestabilidad propia de la economía informal no crea las condiciones para la mínima planificación de un futuro menos incierto en el país.

Ahora bien, la venta ambulante también puede ser entendida como una estrategia del colectivo frente a las condiciones que impone la ciudad. El concepto de estrategia toma en cuenta las coacciones estructurales que pesan sobre los agentes analizadas en el primer apartado, las acciones de un agente individual, pero también "el conjunto de acciones ordenadas en vistas de objetivos a más o menos largo plazo y no necesariamente planteadas como tales, que son producidas por los miembros de un colectivo tal como la familia" (Bourdieu, 2011, p. 33). Es decir, los factores de índole individual y de su entorno en tanto respuestas a las coacciones que sobre ellos pesan. Entre las mismas destacamos las cadenas de comunicación y redes sociales.

En términos generales, las redes y cadenas migratorias de los senegaleses se organizan, estructuran y funcionan de acuerdo a un proceso ascendente que va de la familia nuclear a la familia extensa, y de ahí a la comunidad. Es decir, las redes son de base parental, étnica y geográfica. De acuerdo a Goldberg (2003), se trata de un proyecto en el que se produce una inversión de parte de la economía familiar/comunal, ya que los que logren instalarse en destino asumen la responsabilidad para con su gente de origen: enviar remesas, buscarle trabajo a los que vendrán, proporcionarles a su llegada una cama, dinero y, en muchos casos, también la mercadería necesaria para que empiecen a trabajar en la venta ambulante.

Afirma Ottavia Schmidt que la fuerza y la originalidad de la emigración senegalesa parece residir en la eficiencia en la organización de la solidaridad, que considera de forma negativa el individualismo. "En este sentido, la solidaridad senegalesa no tiene carácter voluntarístico o de emergencia, formaría parte de un estilo y de un sistema de vida que tiene raíces culturales e históricas profundas y que propone valores y modos para realizarlo" (Schmidt, 1994, p. 88-89 en Lacomba Vázquez, 1996, p. 69).

Cuando uno de los jóvenes senegaleses llega a Buenos Aires sin conocimiento de la lengua ni otras pautas culturales, así como tampoco con un capital económico importante para invertir, la actividad a la que tienen más fácil acceso es la venta ambulante, en la cual consiguen insertarse mediante las redes de apoyo del propio colectivo senegalés. Los conocidos llegados con anterioridad, gestionan inmediatamente el préstamo de mercadería, la cual se va devolviendo durante los primeros meses de ventas en Argentina. La venta ambulante les permite, mediante una pequeña inversión de capital, comenzar a trabajar al día siguiente de su llegada, -al principio al lado de un joven con 
mayor experiencia y estadía en el país-, para luego buscar su propio espacio. La inserción en la economía de la venta ambulante de joyas de fantasía, anteojos y otros objetos, presenta varias ventajas: es una mercadería barata para comprar, liviana para transportar, no significa una gran pérdida en caso de ser quitada por la policía. Gran parte de la mercadería la obtienen a través de distribuidores mayoristas senegaleses (Agnelli y Kleidermacher, 2009).

Por último, podemos afirmar que no se trata de una actividad novedosa para el colectivo, ya que algunos integrantes de la comunidad ya realizaban esta actividad en Senegal, por la gran extensión de la economía informal y la falta de oportunidades para insertarse en el mercado formal de trabajo en dicho país. Entre sus motivos, Moreno Maestro (2008) destaca el hundimiento de los tres principales sectores de la economía como consecuencia de la puesta en práctica de políticas de liberalización comercial y de privatizaciones impuestas por el Fondo Monetario Internacional y el Banco Mundial, ellos son: la agricultura, la pesca y el empleo en el sector público. Ello trajo como consecuencia el crecimiento de la economía informal, ${ }^{14}$ fundamental en los sistemas de abastecimiento y distribución de los centros urbanos. La economía informal es visible, es tolerada y fomentada ante la certeza por parte del gobierno de que es la única salida de gran parte de su población y de que un mayor control de esta economía generaría importantes movimientos de protesta.

En conclusión, la venta ambulante, entendida como una estrategia del colectivo senegalés frente a las restricciones para su inserción que ofrece la Ciudad Autónoma de Buenos Aires, incide en la circulación que producen en la ciudad. Esto es: su concentración en los barrios de Once, Flores, Constitución y Liniers principalmente, donde ejercen la venta callejera, lugares donde hay un gran tránsito de personas por ser importantes estaciones de ferrocarriles y buses. Pero también, lugares donde su contacto se restringe a población de bajos recursos, muchos de ellos también migrantes, y donde las posibilidades de ascenso social se ven reducidas.

\section{Palabras finales}

En el presente escrito nos propusimos analizar la circulación de migrantes de origen senegalés en la Ciudad Autónoma de Buenos Aires, teniendo en

\footnotetext{
${ }^{14} \mathrm{La}$ economía informal sería la formada por todas aquellas actividades generadoras de ingresos que no están reguladas por el estado en un medio ambiente social donde actividades similares están reguladas (Portes, 1981). La OIT (2002) define la economía informal como todas las actividades económicas de trabajadores y unidades económicas que no están cubiertas por las disposiciones oficiales que las encuadran.
} 
consideración que se trata de una migración reciente, que arriba afectada por cuestiones económicas -entre otros motivos-, sin capital para invertir, en una ciudad que ha sufrido un proceso de neoliberalización, restringiendo las ayudas estatales y limitando las posibilidades de inserción de los nuevos pobladores.

En ese contexto, reflexionamos respecto a las características de dicho colectivo, entendiendo que las mismas han formado parte de las estrategias para adaptarse a la situación que el destino plantea. Las dificultades en el ámbito laboral los han acercado a la venta ambulante, en el mercado informal de empleo, y su residencia en hoteles pensión, de condiciones habitacionales precarias, y en barrios empobrecidos, y en muchos casos marginados de la ciudad, lo cual designa no solo la concentración de la población en el territorio urbano según su posición social, sino esencialmente las oportunidades diferenciales de acceso a los bienes materiales y simbólicos de la ciudad.

Entendemos que los motivos que dieron lugar a las distintas formas de apropiación del espacio en la ciudad encuentran explicación en un conjunto de factores: económicos (posibilidades de ganarse la vida), de conectividad (posibilidad de emplazamiento que permite acceso a distintos puntos de localización de servicios), de habitabilidad (rasgos físicos del lugar), históricos (preexistencia de un patrón de distribución territorial que gravita en la fisonomía arquitectónica, humana y financiera de los lugares) y políticos (intervención institucional que favorece o penaliza algunas zonas). Ello ha traído como consecuencia el asentamiento de las poblaciones de menores recursos -muchos de ellos migrantes- en un corredor sur-oeste de la capital.

En este sentido, la venta ambulante y la residencia en hoteles pensiones en barrios empobrecidos de la Ciudad de Buenos Aires es el resultado de dichos procesos que tuvieron lugar en la ciudad, y cuya contrapartida es la reducción de oportunidades para este grupo de inmigrantes de integrarse en otros ámbitos, lo cual a la vez es fuente de estigmas, discriminación y exclusión, la cual también pesa sobre otras personas de la ciudad, pero a la cual se suman aspectos propios de la migración proveniente de África, tema analizado en otros escritos.

En pocas palabras, nos hemos propuesto contribuir a explicar el asentamiento y circulación de migrantes senegaleses en determinadas zonas de la ciudad, y su mayor proporción a asentarse en hoteles pensión, en condiciones de habitabilidad precarias. Proponemos que, a los factores culturales propios del colectivo, se adicionan factores económicos de distribución de la ciudad así como factores históricos y políticos que se entrecruzan y dan como resultado esta particular instalación en la Ciudad Autónoma de Buenos Aires. 


\section{Referencias}

AGNELLI, Silvina; KLEIDERMACHER, Gisele. Migración estacional de senegaleses en Mar del Plata. VIII Reunión de Antropología del Mercosur. Bueno Aires, 2009 .

BOURDIEU, Pierre. La distinción: criterios y bases sociales del gusto. Buenos Aires: Taurus, 1988.

BOURDIEU, Pierre. Las estrategias de la reproducción social. Buenos Aires: Siglo Veintiuno Editores, 2011.

BOURDIEU, Pierre; WACQUANT, Loïc. Réponses: pour une anthropologie réflexive. Paris: Seuil, 1992.

CHECA, Francisco. Oportunidades socioeconómicas en el proceso migratorio de los inmigrantes africanos en Almería. Agricultura y sociedad, n. 77, p. 41-82, 1995.

CICCOLELLA, Pablo. Buenos Aires: una metrópolis postsocial en el contexto de la economía global. In: Pedro Pirez (Ed.). Buenos Aires, la formación del presente. Quito: Olachi, 2009.

CRESPO, Rafael. Los "mòodu-mòodu" y su impacto en la sociedad de origen. In: Joaquín Beltrán y Natalia Ribas (Ed.). Empresariado étnico en España. Ministerio de Trabajo y Asuntos Sociales, Subdirección General de Información Administrativa y Publicaciones, 2007.

CUENYA, Beatriz; CLICHEVSKY, Nora; PUGLIESE, Luciano. Inquilinatos en la Ciudad de Buenos Aires: Referentes teóricos e históricos y un estudio de caso en el barrio de Almagro. Buenos Aires: Centro de Estudios Urbanos y Regionales, 1988.

GOLDBERG, Alejandro. Ser inmigrante no es una enfermedad: inmigración, condiciones de vida y de trabajo - el proceso de salud/enfermedad/atención de los inmigrantes senegaleses en Barcelona. Tesis de Doctorado. Facultad de Letras Departamento de Antropología, Filosofía y Trabajo Social, Universitat Rovira i Virgili, Tortosa, 2007.

KABUNDA, Mbye. Las instituciones financieras internacionales en África. Pueblos. Revista de información y Debate, n. 51, $2012<\mathrm{http}$ ://revistapueblos.org/old/spip. php?article2418>.

KAPLAN, Adriana. Los procesos migratorios: senegambinos en Cataluña. Barcelona, mosaico de Culturas. Barcelona: Museu Etnologic, 2003.

KLEIDERMACHER, Gisele. Entre cofradías y venta ambulante: una caracterización de la inmigración senegalesa en Buenos Aires. Cuadernos de Antropología Social, n. 38, p. 109-130, 2013.

LACOMBA VÁZQUEZ, Joan. Identidad y religión en inmigración: a propósito de las estrategias de inserción de los musulmanes senegaleses. Alternativas - Cuadernos de Trabajo Social, n. 4, p. 59-76, 1996.

MAFFIA, Marta; AGNELLI, Silvina. Primeras aproximaciones al estudio de la nueva inmigración africana en la Argentina. Anuario en Relaciones Internacionales (IRI). La Plata: Ediciones IRI-UNLP, 2008. p. 1-9. 
MÁRMORA, Lelio. Las politicas de migraciones internacionales. Buenos Aires: Paidós, 2004.

MAZZEO, Victoria; ROGGI, María Cecilia. Los habitantes de hoteles familiares, pensiones, inquilinatos y casas tomadas de la Ciudad de Buenos Aires: ¿dónde están?, ¿de dónde vienen?, ¿quiénes son? y ¿cómo viven?”. Revista Población de Buenos Aires, v. 9, n. 15, p. 7-28, 2012.

MORENO MAESTRO, Susana. Mujeres senegalesas y economía informal en Sevilla. Repercusiones en los roles de género. I Congreso Internacional sobre Género, Trabajo y Economía Informal, 2008. p. 27-29.

PÍREZ, Pedro. La privatización de la expansión metropolitana en Buenos Aires. Economía, Sociedad y Territorio, v. 6, n. 21, p. 31-54, $2006<10.22136 /$ est002006272>.

PÍREZ, Pedro. La privatización de la expansión metropolitana de Buenos Aires. In: Pedro Pírez (Ed.). Buenos Aires, la formación del presente. Quito: Olachi, 2009.

PORTES, Alejandro. Modes of structural incorporation and present theories of labor immigration. In: Mary Kritz; Charles Keely; Silvano Tomasi. Global trends in migration: theory and research on international population movements. New York: Center for Migration Studies, 1981. p.279-397.

RODRÍGUEZ, Gonzalo. Segregación residencial socioeconómica en la Ciudad Autónoma de Buenos Aires: dimensiones y cambios entre 1991-2001. Revista Población de Buenos Aires, v. 5, n. 8, p. 7-30, 2008.

SCHMIDT, Ottavia. Islam, solidarietá e lavoro: i muridi senegalesi in Italia. Torino: Fondazione Giovanni Agnelli, 1994.

STRAUSS, Anselm; CORBIN, Juliet. Bases de la investigación cualitativa: técnicas y procedimientos para desarrollar la teoría fundamentada. Antioquia: Universidad de Antioquia, 2002.

WACQUANT, Lois. La estigmatización territorial en la edad de la marginalidad avanzada. Ciencias Sociais Unisinos, v. 43, n. 3, p. 193-199, 2007.

Recibido el: 28 sept. 2016

Aprobado el: 7 jul. 2017

Autora correspondiente:

Gisele Kleidermacher

Pres. José Evaristo Uriburu 950, 6to piso, Oficina 24

C1114AAD Ciudad Autónoma de Buenos Aires, Argentina 